\title{
Demand Response Programs Management in an Energy Community with Diversity of Appliances
}

\author{
Rúben Barreto ${ }^{1}$, Pedro Faria ${ }^{1, *}$, and Zita Vale $^{1}$ \\ ${ }^{1}$ Polytechnic of Porto, Porto, Portugal
}

\begin{abstract}
This paper shows the behaviour of a Demand Response program designed to be implemented in Energy Communities, where they take advantage of photovoltaic production. The primary objective is to manage both photovoltaic overproduction and village consumption efficiently. The DR program focuses on looking for consecutive periods that exceed a target peak set by the aggregator after analysing the consumption of the given energy community. The case study includes three villages, where participants are expected to be members of a community. The results are that participants will see a reduction in costs and electricity consumption.
\end{abstract}

\section{Nomenclature \\ Acronyms \\ AC - Air Conditioner \\ DW - Dishwasher \\ FH - Fan Heater \\ IL - Initial Load \\ PC - Pretended Cut \\ PV - Photovoltaic \\ WH - Water Heater \\ WM - Washing Machine \\ Parameters}

$\mathrm{K}$ - Number of allowed consecutive periods in an event

$\mathrm{Pa}(\mathrm{t}) \quad$ - Consumption of the Appliance a

$\operatorname{Ppv}(\mathrm{t}) \quad$ - Consumption of the Photovoltaic

Variables

Dpi(t) - Change in the consumption after applying reduction of appliance type $i$

$\mathrm{Ta}(\mathrm{t}) \quad$ - Total consumption related to appliance a

$\mathrm{TRa}(\mathrm{t}) \quad$ - Total of the reductions of the appliance a

TPV $(\mathrm{t})$ - Total production from Photovoltaic

Indexes
a
- Appliances (WH, AC, FH, WM, DW)
i $\quad-(1,2,3,4,5)$
$\mathrm{n} \quad$ - Number of participants

* Corresponding author: pnf@isep.ipp.pt 


\section{Introduction}

During the development of the electricity sector, a great deal of attention is paid to decentralized and distributed electrical systems that are supported by renewable energy [1]. Given the context of this role, concepts such as Demand Response (DR) and Smart Grids (SG) are crucial to developing a sustainable electrical system.

In the context of this paper, SGs, through two-way communication technologies implemented in electrical systems, can monitor all processes from electricity generation to distribution in public or private buildings [2]. With the implementation of SG, there is greater control of the electricity grid, allowing the integration of renewable energy does not compromise the efficiency and reliability of the electricity system itself [3]. However, for the implementation of SG to be efficient, another concept, DR, needs to be used.

This concept is a program that incites consumers to strategically regulate the pattern of electricity consumption to induce lower electricity use in periods where the price of electricity in the market is high or when it is intended to mitigate network anomalies. Thus, the DR concept improves the efficiency and flexibility of resource management [4], [5]. In a community of energy, it can sometimes be verified that the inhabitants take advantage of the use of renewable energies, where they, besides consuming energy can also produce it, thus allowing later the sale of electricity in case of excess of energy production - these inhabitants, designated as "prosumers" [6], can be either a public or a private building. However, there are difficulties in determining a group of inhabitants who can support an energy community [7].

Regarding the contribution of the present paper, it is a continuation of the paper [8], where it presents new data from other energy communities that make use of decentralized electrical systems. On the other hand, the DR method developed in this paper only applies if there is a set of consecutive periods with consumption higher than a limit imposed by the aggregator. In this way, the DR method is only applied at times of greatest need.

Section I depicts the introduction to the theme and the primary purpose of the paper in question. Section II, it serves to show the flowchart of the methodology discussed, where it explains the different phases of the proposed model as well as how to obtain the values of consumptions and productions of the PV panels and also how to apply reductions. Section III describes in detail the case of study of this article. The results of the selected scenario will be analysed in Section IV. Finally, Section V presents the main conclusions drawn from the work developed.

\section{Approach}

In this section, the proposed methodology will be presented in a detailed manner. Fig. 1 shows the proposed methodology.

\subsection{Problem Formulation}

The methodology presented consists of 4 steps, where initially, it is necessary to acquire the data of consumption and production of photovoltaic (PV) panels of the participants, which are either residential or public buildings. Most of the PV generation values come from public buildings. However, some houses also are equipped with PV panels. The consumption expenditure of each participant is determined by the aid of the tariff it provides. This information is collected in 15-minute periods, where at the end of the day, it totals 96 periods. 


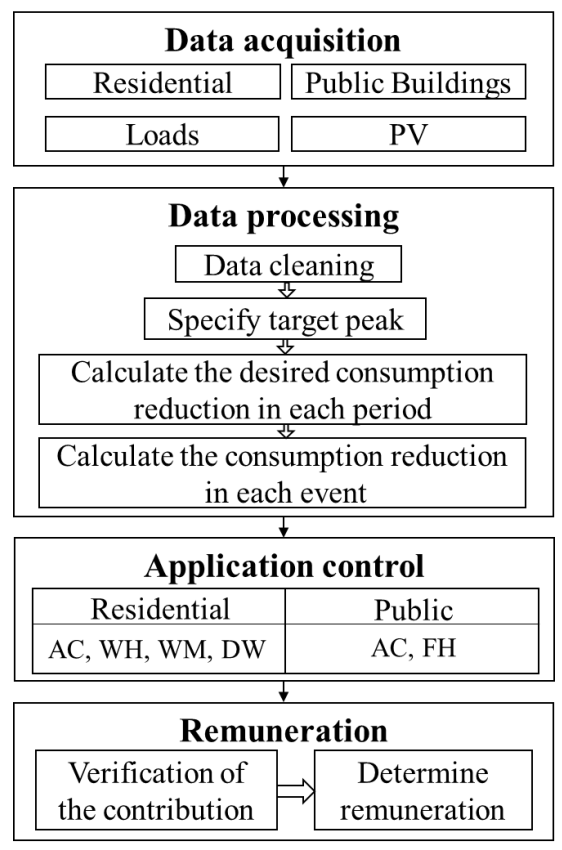

Fig. 1. Proposed Methodology.

Regarding the Data processing stage, it consists of 4 phases, the first of which is to verify, by period $\mathbf{t}$, the own consumptions provided by the participants, to find values that do not fit the other data and correct them. That is, sometimes they find themselves values that are very high concerning the others, and through the average daily consumption, determines if a new value that can replace the discrepancy. This way, it is possible to use the consumptions correctly, by gathering, by period $\mathbf{t}$, the consumptions of the $\mathbf{n}$ participants per equipment a, to obtain the total consumption of each device $\left(\mathrm{T}_{\mathrm{a}}\right)$, as can be seen in (1). Subsequently, it becomes possible to determine the total consumption of the $\mathbf{N}$ varieties of equipment used that represents the initial load (IL) of the energy community in question, for period $\mathbf{t}$, as shown in (2).

$$
\begin{aligned}
& T_{\mathrm{a}}(t)=\sum_{x=1}^{\mathrm{n}} P_{\mathrm{a}(x)}(t) \\
& I L(t)=\sum^{\mathrm{N}}{ }_{x=1} T_{\mathrm{a}(x)}(t)
\end{aligned}
$$

Then comes the Specify target peak phase, where, after analysing the new data, a target peak is specified from which equipment reductions will be made at certain times when they exceed the target peak. As for the third phase, it consists of calculating the desired consumption reduction in each period $\mathbf{t}$, that is, determining the Pretended Cut (PC) that will be implemented in each of the consecutive periods in which it is verified that the IL of the community is above the specified target peak, using equations (3) and (4). If the PC value is above the specified target peak, reductions in equipment are applied, through equations (5) and (6), in an orderly and indiscriminate manner, until community consumption reaches a value equal to or less than the target peak. These reductions in the consumption of specific equipment are total so as not to benefit some participants and harm others. Equation (3) represents the total PV production of the $\mathbf{m}$ existing panels in the respective community, in each period $\mathbf{t}$.

$$
T P V(t)=\sum_{x=1}^{\mathrm{m}} P_{\mathrm{pv}(x)}(t)
$$




$$
P C(t)=I L(t)-T P V(t)
$$

As there is an order in the equipment reductions, the first reduction is made in Water Heater (WH), i.e., for $\mathrm{TR}_{\mathrm{a}(1)}$.

$$
D \mathrm{p}_{1}(t)=P C(t)-T R_{\mathrm{WH}}(t)
$$

For the second $(\mathrm{i}=2)$ to the fifth reduction, it is:

$$
D \mathrm{p}_{i}(t)=D \mathrm{p}_{(i-1)}(t)-T R_{\mathrm{a}(i)}(t)
$$

Where a(i) represents the respective equipment according to the value of $i$, and for the case of $\mathrm{i}=2$, this represents the Air Conditioner (AC). As $\mathrm{i}$ increases, a(i) moves to the following equipment. As for the last phase of this step, this is to calculate the reduction in each event $\mathbf{K}$, where this parameter represents, to a certain extent, the number of consecutive periods. That is, an event is when it turns out that there is $\mathbf{x}$ number of consecutive periods exceeding the target peak value. With this parameter, it is then possible to avoid making reductions full time, thus allowing only to act in the moments of greatest need. Regarding the third step, it consists of applying the calculated reductions in the equipment in each building that contributes to the study, indiscriminately, in each period $\mathbf{t}$. In other words, the reductions are applied to all consumers who have cut-off values, enabling the community to reach a new value that is as close as possible to the desired reference peak value. Finally comes the Remuneration step, which firstly finds out which participants made the reductions in the devices when they needed to be cut. Subsequently, considering the total reduction made by the community and the total amount of reduction of each participant throughout the day, the percentage value of each participant's contribution is determined, thus influencing their respective remuneration.

\subsection{Load Monitoring and Control}

One device that was of crucial importance in this paper is the smart plug, as it allows us to obtain the consumption values of the respective equipment as well as to capture the production of PV panels. On the other hand, smart plugs can be used to disable specific appliances, thus reducing power consumption at the time it is requested [9]. This equipment is responsible for turning off WH, Fan Heater (FH), Washing Machine (WM), and Dishwasher (DW).

\section{Case Study}

The case study will be based on three network communities from villages A, B, and C situated in Portugal. Table 1 shows the information from the villages, where $\mathrm{R}$ represents the residential consumers and $\mathrm{P}$, the public buildings. This table indicates, for each type of consumer in the respective village, the total number of each existing equipment in the community and demonstrates the total power consumption of the equipment itself. On the other hand, this table illustrates the total amount consumed by each type of consumer, as well as the amount of each participant type and the value of the amount of variety of handsets in which the study was controlled. As can be seen, village $\mathrm{C}$ has no public buildings. Table 2 brings the information of village $\mathrm{C}$, where reveals the number of units each consumer has of equipment as well shows the total power spent by the loads and the total power consumed by all the appliances, for a day and in $\mathrm{kW}$. On the other hand, it highlights what the types of devices that were used to carry out the study in this village are. With Table 3, it is possible to verify the different scenarios, where the first column 
indicates the peak reached by village B that will later be used to test the different scenarios. The second one shows the target peak value chosen after the community analysis. If consecutive periods of the IL curve exceed the peak value, the instruments will suffer a reduction in consumption. The third column indicates the number of periods that exceeded the value of the previous column. Finally, the fourth column illustrates the percentage added to the base value, (B), produced by the PV panels. With the increase in the base value, it allows simulating days where is higher PV generation. Through the equations presented in section 2, it is possible to elaborate the graphs illustrated in Figs. 2, 3, and 4. These figures illustrate, for each village, the consumption of the appliances and the rigid load (RL), as well as the PV generation.

Table 1. Information of the Villages.

\begin{tabular}{|l|c|c|c|c|c|}
\cline { 2 - 6 } \multicolumn{1}{c|}{} & \multicolumn{2}{c|}{$\mathbf{A}$} & \multicolumn{2}{c|}{ B } & C \\
\cline { 2 - 6 } \multicolumn{1}{c|}{} & $\mathbf{R}$ & $\mathbf{P}$ & $\mathbf{R}$ & $\mathbf{P}$ & $\mathbf{R}$ \\
\hline \#PV & 4 & 3 & - & 4 & 4 \\
\hline P.PV (kW) & 6.0 & 15.0 & - & 12.0 & 6.0 \\
\hline \#AC & 40 & 21 & - & 7 & 4 \\
\hline P.ACs (kW) & 97.4 & 1295.5 & - & 285 & 111.5 \\
\hline \#WH & 9 & - & 10 & - & 10 \\
\hline P.WH (kW) & 21.3 & - & 34.6 & - & 28.5 \\
\hline \#FH & - & 4 & - & 24 & - \\
\hline P.FH (kW) & - & 45.6 & - & 272 & - \\
\hline \#WM & 7 & - & 7 & - & 3 \\
\hline P.WM (kW) & 14.2 & - & 32.2 & - & 8.2 \\
\hline \#DW & 14 & - & - & - & - \\
\hline P.DW (kW) & 18.0 & - & - & - & - \\
\hline Total Power (kW) & 1020.4 & 1997.6 & 531.6 & 1867.2 & 713.7 \\
\hline \#Type of Appliance & 5 & 4 & 3 & & \\
\hline \#Consumers & 23 & 4 & 12 & 4 & 13 \\
\hline
\end{tabular}

Table 2. Information of the Consumers of Village $\mathrm{C}$.

\begin{tabular}{|l|c|c|c|c|c|c|c|c|c|}
\hline Consumer & $\# \mathbf{P V}$ & $\begin{array}{c}\mathbf{P V} \\
\mathbf{k W}\end{array}$ & \#AC & $\begin{array}{c}\text { AC } \\
(\mathbf{k W})\end{array}$ & \#WH & $\begin{array}{c}\mathbf{W H} \\
\mathbf{( k W )}\end{array}$ & \#WM & $\begin{array}{c}\mathbf{W M} \\
\mathbf{( k W )}\end{array}$ & $\begin{array}{c}\text { Total Power } \\
(\mathbf{k W})\end{array}$ \\
\hline House 1 & - & - & - & - & 1 & 1.54 & - & - & 42.75 \\
\hline House 2 & - & - & - & - & - & - & - & - & 9.60 \\
\hline House 3 & - & - & - & - & 1 & 1.78 & 1 & 0.63 & 37.78 \\
\hline House 4 & 1 & 1.5 & 1 & 22 & 1 & 5.04 & - & - & 84.79 \\
\hline House 5 & - & - & - & - & 1 & 3.26 & - & - & 61.99 \\
\hline House 6 & - & - & - & - & 1 & 1.67 & - & - & 38.70 \\
\hline House 7 & - & - & - & - & - & - & - & - & 8.97 \\
\hline House 8 & - & - & - & - & - & - & - & - & 37.18 \\
\hline House 9 & 1 & 1.5 & 1 & 28 & 1 & 1.39 & - & - & 86.72 \\
\hline House 10 & 1 & 1.5 & 1 & 34.5 & 1 & 3.57 & 1 & 3.76 & 102.68 \\
\hline House 11 & - & - & - & - & 1 & 2.66 & - & - & 51.42 \\
\hline House 12 & 1 & 1.5 & 1 & 27 & 1 & 6.13 & - & - & 89.05 \\
\hline House 13 & - & - & - & - & 1 & 1.46 & 1 & 3.82 & 62.02 \\
\hline
\end{tabular}

Table 3. Scenario Description.

Scenario 1

Scenario 2

Scenario 3

Scenario 4

\begin{tabular}{|l|l|l|l|}
\hline Peak Load $(\mathrm{kW})$ & Target Peak $(\mathrm{kW})$ & $\mathrm{N}^{\circ}$ of activation periods & $\mathrm{PV}(\%)$ \\
\hline
\end{tabular}

51.7

\begin{tabular}{|c|c|c|}
\hline 40 & 12 & $\mathrm{~B}$ \\
\hline 37 & 19 & $\mathrm{~B}^{*} 150$ \\
\hline 35 & 21 & $\mathrm{~B}$ \\
\hline 35 & 21 & $\mathrm{~B}^{*} 150$ \\
\hline
\end{tabular}


Thus, with the equations shown in Section II, the graphs are elaborated in Figs. 2, 3, and 4. The first letter of the elements of the figure caption, $\mathrm{S}$, represents the respective total consumption of the rigid load (RL) and appliances, and the total production of the PV panels (TPV) of the three villages in one day.

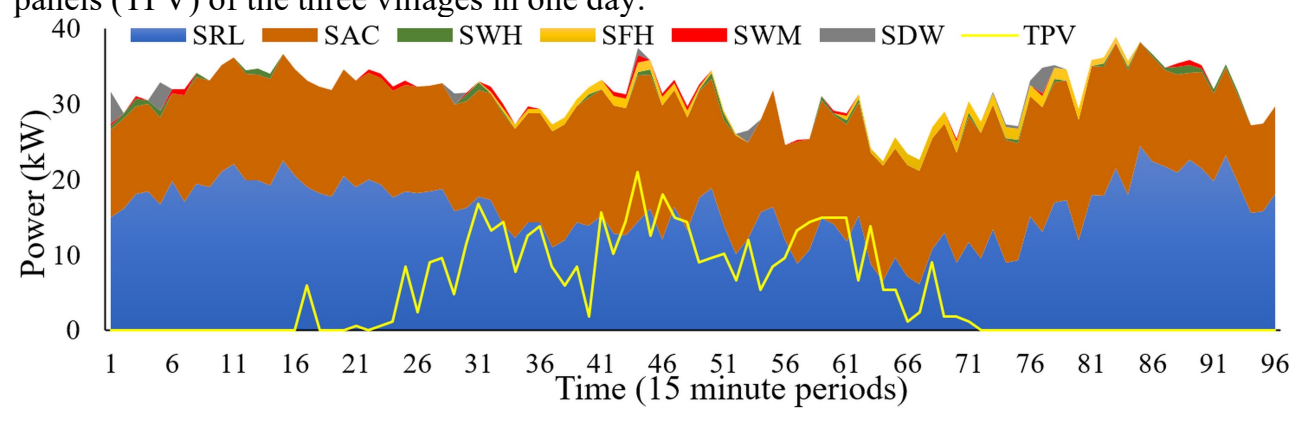

Fig. 2. Behaviour of the Appliances and PV on the Village A.

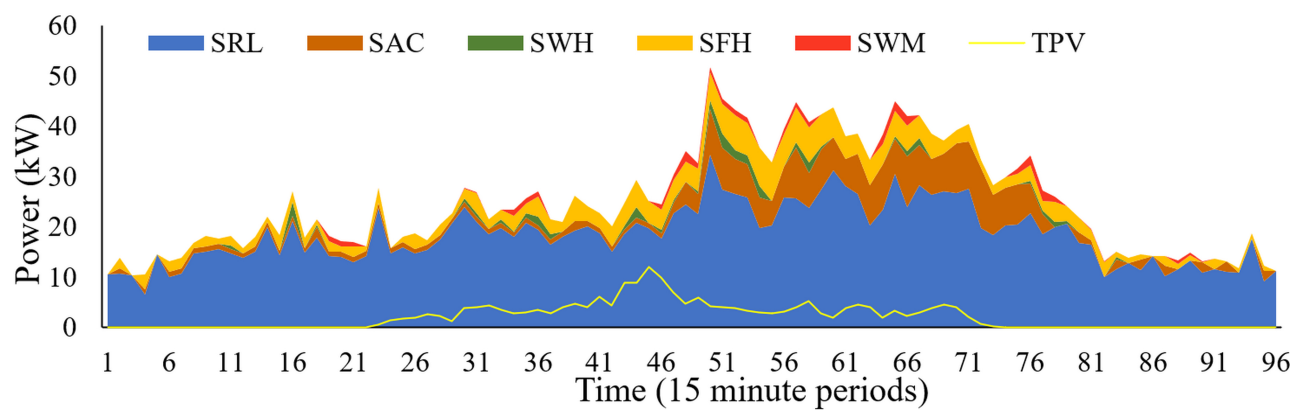

Fig. 3. Behaviour of the Appliances and PV on the Village B.

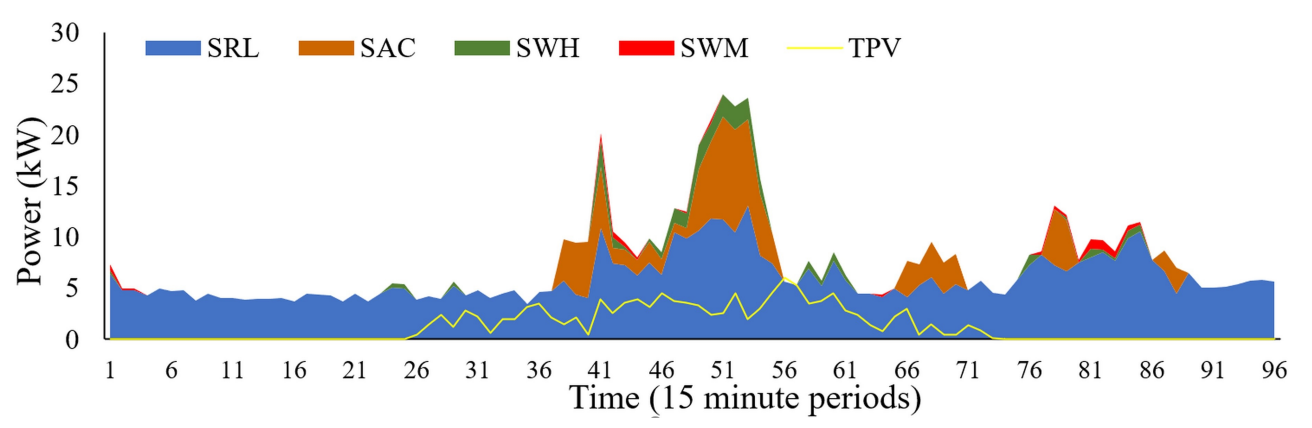

Fig. 4. Behaviour of the Appliances and PV on the Village C.

\section{Results}

In this section is analysed the different scenarios established and the behaviour of the villages.

\subsection{Village $B$}

Initially, to test the different scenarios, we use only the data from village B to draw the different graphs that allow us to draw conclusions about the scenarios. The parameter $\mathrm{K}$ of 8 is used. Fig. 5 illustrates the variation between the initial (SIL) and final (SFL) total community consumption. The total rigid load, SRL, represents the uncontrolled 
consumptions, and the flexible load, SFlexL, represents the consumption of all equipment related to this study. As for TPV, it represents the total power output of the 4 PV panels from village B throughout the day. The SFL represents the SIL after the equipment reductions, while Grid represents the same as the SFL but still implements the TPV to the SIL. Where the SFL values are different from SIL, this means that photovoltaic production was not sufficient to reduce these consumptions to the set reference value, being necessary to make the reductions in the devices.

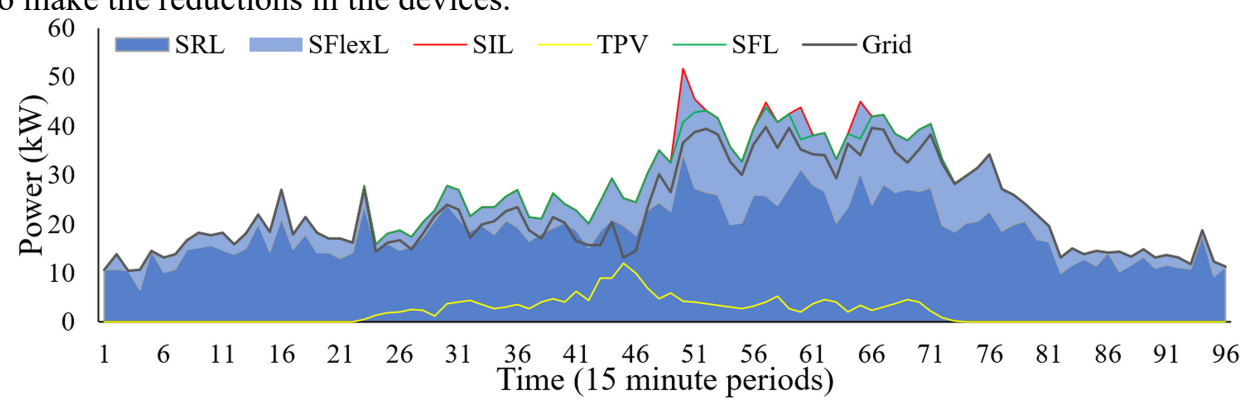

Fig. 5. Initial and Final consumption of Village B, Scenario 1.

The graphs shown in Figs. 6 and 7 are used to compare the daily consumption of the largest Residential and Public consumers, highlighting both the type of equipment they use and the magnitude of their consumption. IL represents the consumption, while the elements starting with the letter $\mathrm{C}$ represent the reductions made in the respective equipment.

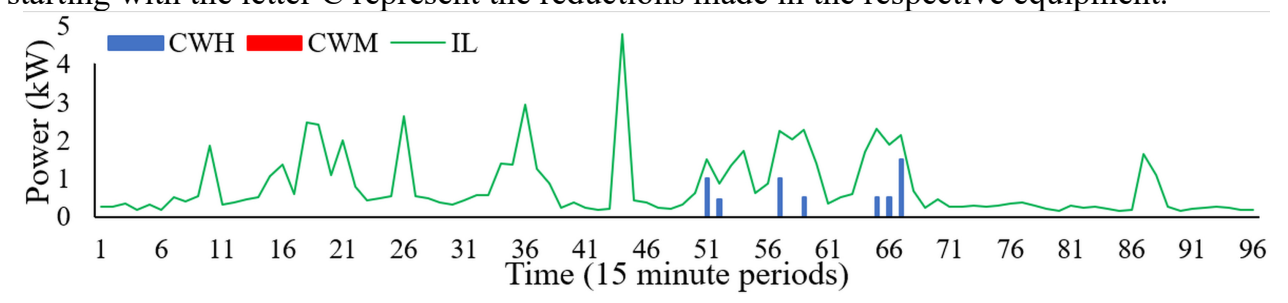

Fig. 6. Largest Residential Consumer of Village B, Scenario 2.

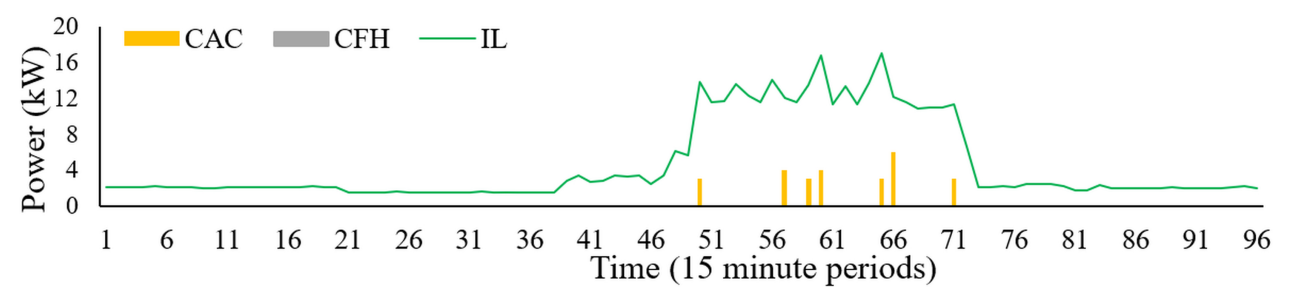

Fig. 7. Largest Public Consumer of Village B, Scenario 2.

Fig. 8 illustrates which equipment has been reduced in scenario 3. For the first equipment, $\mathrm{WH}$, only houses have them, so there are no reductions in the last four consumers that represent public buildings. In village $\mathrm{B}$, the $\mathrm{AC}$ and $\mathrm{FH}$ are only present in public, where these are the ones that have the highest cutting capacity due to their high consumption of the others. After applying the reductions of this equipment, we can conclude that it was possible to reduce the expenditure to the previously established reference value, making it not necessary to make reductions in the WM. Fig. 9 highlights the quantity of times event $\mathrm{K}$ occurred in each of the scenarios tested in village $\mathrm{B}$. As can be seen, as the target peak value decreases, the number of consecutive periods with size K occurs most often. Different reactions have been achieved in the scenarios of village B. In the last two scenarios, was found that increasing the PV production from one scenario to 
another, the peak in both after the device reductions is higher, which means that the increase in the base value of the PV was able to reduce the consumption to the desired value.

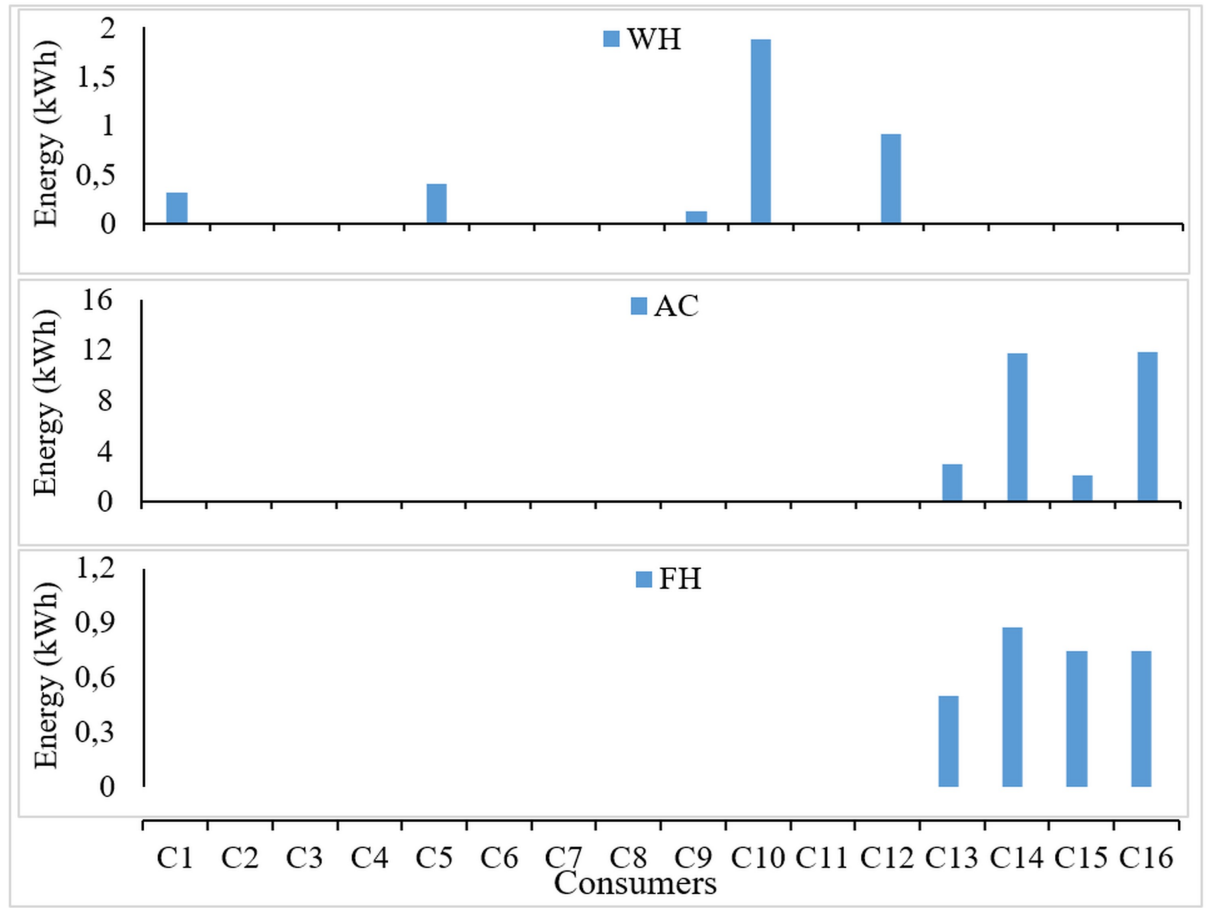

Fig. 8. Reductions applied to each consumer device in Village B, Scenario 3.

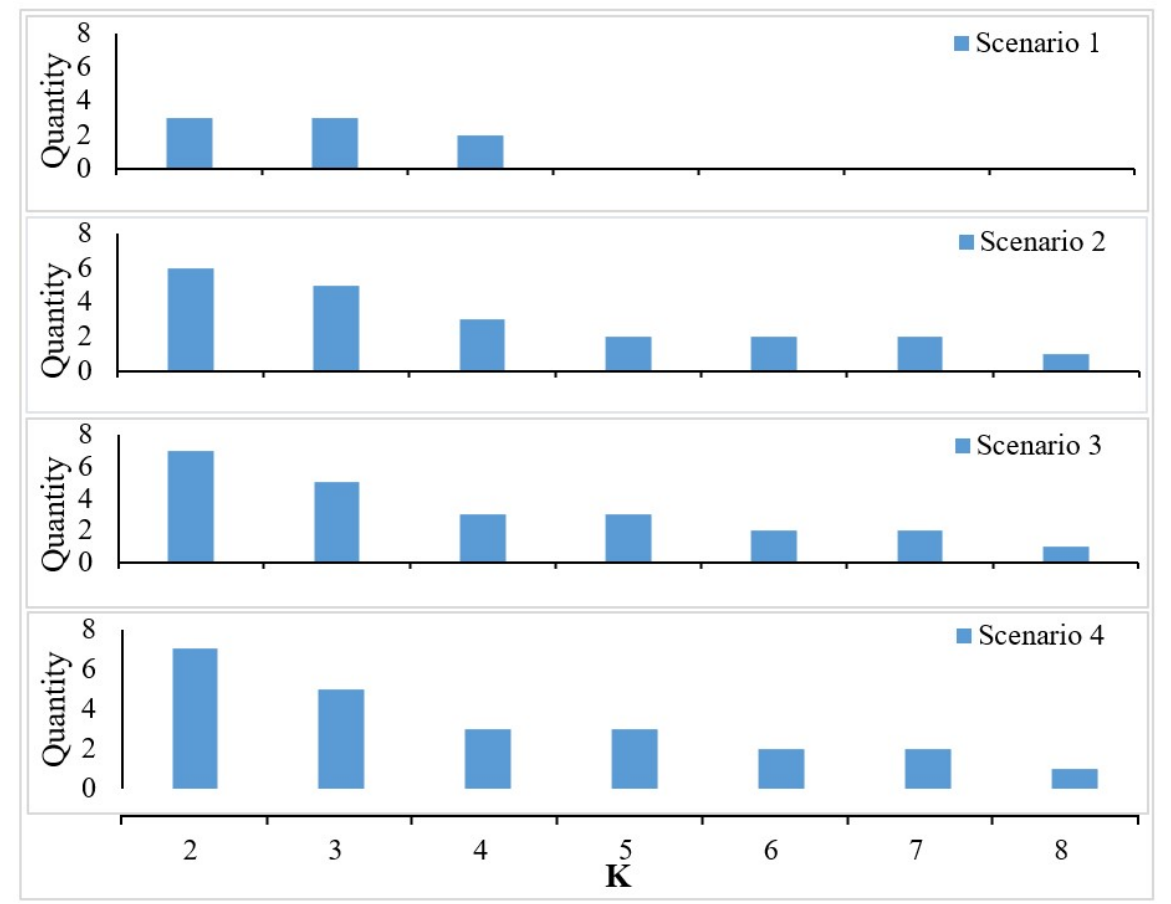

Fig. 9. Number of events of K occurred in each Scenario. 
It was also found that as the target peak value decreases, equipment reductions are more relevant, even in scenario 2, where the base value of PV production has increased. In the latter scenario, the increase in PV base production compensated to such an extent that it was even found that the reductions in appliances were lower than the previous scenario.

\subsection{Villages}

It is used scenario 4 to compare the results since, in this case, more devices were responding to DR events as it was also the case where there were more activated DR events. In this way, Fig. 10, Fig. 11, and Fig. 12 presents the scheduling results in village $A$, village $B$, and village $C$, respectively.

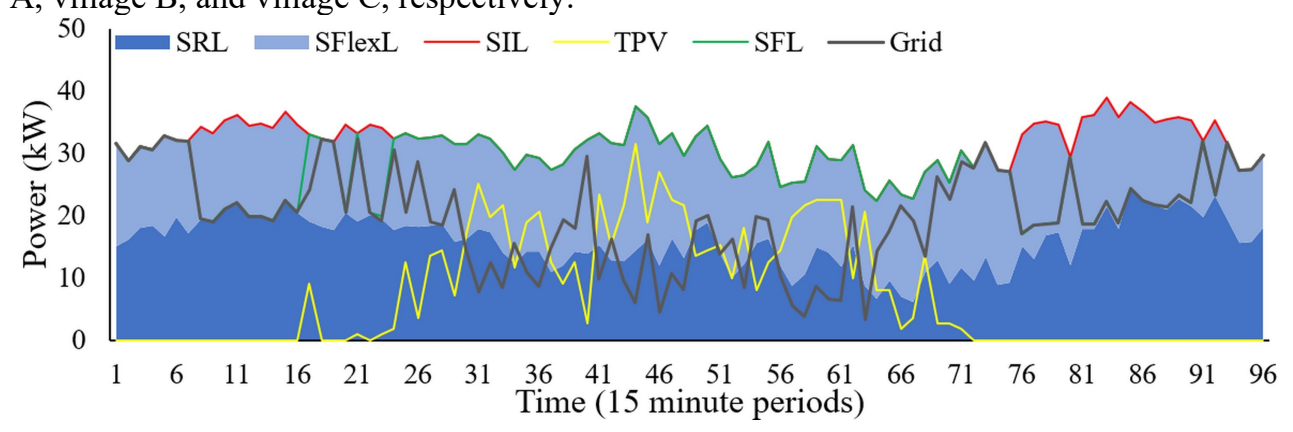

Fig. 10. Village A, Scenario 4.

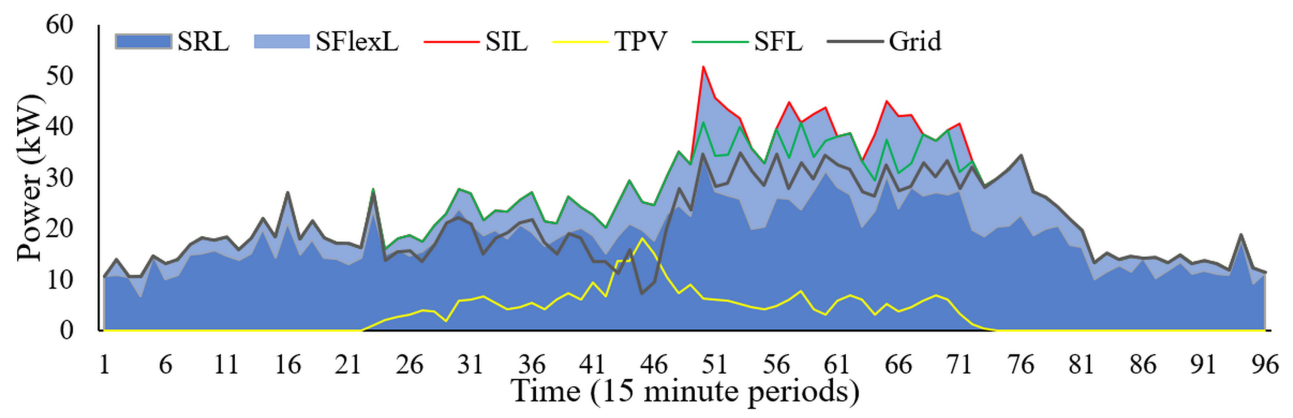

Fig. 11. Village B, Scenario 4.

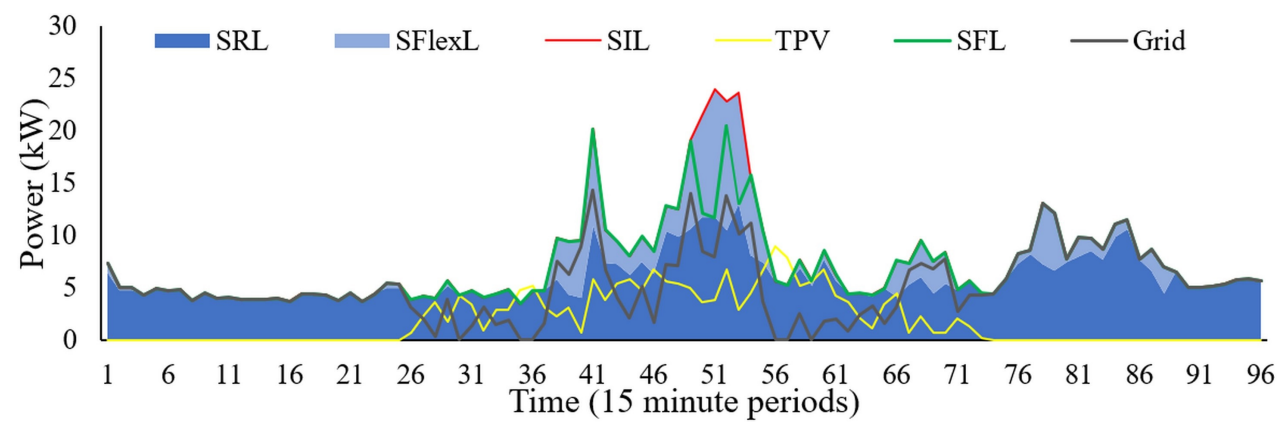

Fig. 12. Village C, Scenario 4.

In order to get a sense of how much each village earns in compensation due to photovoltaic production, Table 4 highlights how much each village invoices for each scenario. It can be seen that the different villages will receive different remuneration of participation in DR events, by providing load reduction in the different scenarios. It is due 
to the influence of the available PV generation and also to the different defined target peaks that imply on the activated amount of DR.

Table 4. Remuneration of the Villages.

\begin{tabular}{|c|c|c|}
\cline { 2 - 3 } \multicolumn{1}{c|}{} & \multicolumn{2}{c|}{ Scenario } \\
\cline { 2 - 3 } \multicolumn{1}{c|}{} & 1 and 3 & 2 and 4 \\
\hline $\mathrm{A}$ & $15,88 €$ & $23,81 €$ \\
\hline $\mathrm{B}$ & $6,70 €$ & $10,04 €$ \\
\hline $\mathrm{C}$ & $4,04 €$ & $6,07 €$ \\
\hline
\end{tabular}

\section{Conclusion}

The method implemented seeks to distribute the surpluses equitably and effectively among the other participants, through the participants who can produce energy. The different results illustrated demonstrate, for each scenario, the performance of the DR program developed. The DR program developed during community consumption management is used to reduce only consecutive periods that exceed the respective target peak established for each scenario. Consequently, the members that implemented the reductions at the time they were requested obtain benefits from photovoltaic production from other members, depending on their contribution to the study. This paper also illustrates the compensation of each village earned in one day by implementing the proposed methodology. The duration of DR events has been discussed, which will imply the response of consumers.

This work has received funding from Portugal 2020 under SPEAR project (NORTE-01-0247FEDER-040224), from H2020 DOMINOES project, and from FEDER Funds through COMPETE program and from National Funds through (FCT) under the project UIDB/00760/2020, and CEECIND/02887/2017.

\section{References}

1. C. Silva, P. Faria, and Z. Vale, "Discussing Different Clustering Methods for the Aggregation of Demand Response and Distributed Generation", IEEE Symposium Series on Computational Intelligence, (2018). DOI: 10.1109/SSCI.2018.8628781

2. P. Kong, "Cost Efficient Data Aggregation Point Placement With Interdependent Communication and Power Networks in Smart Grid", IEEE Transactions on Smart Grid, 10, pp. 74-83, (2019). DOI: 10.1109/TSG.2017.2731988

3. H. Sharma and G. Kaur, "Optimization and simulation of smart grid distributed generation: A case study of university campus", 4th IEEE Int Conf Smart Energy Grid Eng, pp. 153-157, (2016). DOI: 10.1109/SEGE.2016.7589517

4. M. B. Anwar, D. J. Burke and M. J. O’Malley, "A Multi-Perspective Model for Evaluation of Residential Thermal Demand Response", IEEE Transactions on Smart Grid, 10, pp. 6214-6227, (2019). DOI: 10.1109/TSG.2019.2899780

5. F. Salah, R. Henríquez, G. Wenzel, D. E. Olivares, M. Negrete-Pincetic and C. Weinhardt, "Portfolio Design of a Demand Response Aggregator With Satisficing Consumers," IEEE Transactions on Smart Grid, 10, pp. 2475-2484, (2019). DOI: 10.1109/TSG.2018.2799822

6. G. El Rahi, S. R. Etesami, W. Saad, N. B. Mandayam and H. V. Poor, "Managing Price Uncertainty in Prosumer-Centric Energy Trading: A Prospect-Theoretic Stackelberg Game Approach", IEEE Transactions on Smart Grid, 10, pp. 702-713, (2019). DOI: 10.1109/TSG.2017.2750706 
7. O. Abrishambaf, P. Faria, and Z. Vale, "SCADA Office Building Implementation in the Context of an Aggregator", IEEE 16th International Conference on Industrial Informatics, pp. 984-989, (2018). DOI: 10.1109/INDIN.2018.8471957

8. P. Faria, R. Barreto and Z. Vale, "Demand Response in Energy Communities Considering the Share of Photovoltaic Generation from Public Buildings", International Conference on Smart Energy Systems and Technologies, pp. 1-6, (2019). DOI: 10.1109/SEST.2019.8849082

9. S. Heo, W. Park and I. Lee, "Energy management based on communication of smart plugs and inverter for smart home systems", International Conference on Information and Communication Technology Convergence, Jeju, pp. 810-812, (2017). DOI: 10.1109/ICTC.2017.8190788 